\title{
Resistance of sheep from different genetic groups to gastrointestinal nematodes in the state of São Paulo, Brazil
}

\author{
T.C. Gonçalves ${ }^{\mathrm{a}}$, M.M. Alencar ${ }^{\mathrm{b}}$, R. Giglioti ${ }^{\mathrm{a}, *}$, T.B. Bilhassi ${ }^{\mathrm{a}}$, H.N. Oliveira ${ }^{\mathrm{a}}$, M.D. Rabelo ${ }^{\mathrm{b}}$, \\ S.N. Esteves ${ }^{\mathrm{b}}$, M.C.S. Oliveira ${ }^{\mathrm{b}}$ \\ ${ }^{a}$ Faculdade de Ciências Agrárias e Veterinárias, Universidade Estadual Paulista Júlio de Mesquita Filho, Via de Acesso Prof. Paulo Donato Castellane, s/n, CEP 14884- \\ 900, Jaboticabal, SP, Brazil \\ b Embrapa Pecuária Sudeste (CPPSE), Rod. Washington Luiz, Km 234, CP 339, CEP 13560-970, São Carlos, SP, Brazil
}

\section{A R T I C L E I N F O}

\section{Keywords:}

Fecal egg counts

Sheep

Gastrointestinal parasites

Genetic groups

Susceptibility

\begin{abstract}
A B S T R A C T
Infections by gastrointestinal nematodes cause large losses to sheep breeders. In the study reported here, the resistance to gastrointestinal nematodes was analyzed in sheep of adapted and non-adapted breeds, maintained in naturally infected pastures. A total of 134 females from seven genetic groups were monitored during 20 months: Santa Inês (OSI), Dorper (ODO), Texel (OTX), Ile de France (OIF), and animals from crosses of Santa Inês ewes with Dorper (ODS), Texel (OTS) and Ile de France (OIS) rams. Blood samples were collected monthly to determine the packed cell volume (PCV), and feces were collected at the same time to count the eggs per gram (fecal egg counts $=$ FEC) and identify the genera of the prevalent parasites. The statistical analyses of the data showed significant differences $(p<0.05)$ regarding the genetic group, collection month and interaction of month with the genetic group on the FEC. The correlation estimates between FEC and PCV were negative and significant $(p<0.01)$.The OTS genetic group presented the lowest mean of FEC value. Concerning the nematode genera, the greatest prevalence was observed for Haemonchus spp. (85.6\%), followed by Trichostrongylus spp. (10.8\%), Oesophagostomum spp. (2.9\%) and Cooperia spp. $(0.7 \%)$. The results obtained in this study show that the crossing of the Texel and Santa Inês breeds can be considered an alternative for sheep production in the Southeast region of Brazil due to the lower egg output by gastrointestinal nematodes.
\end{abstract}

\section{Introduction}

Infection by gastrointestinal nematodes (GINs) causes severe losses to sheep breeders in tropical and subtropical regions of the world (Perry et al., 2002; Emery et al., 2016). Parasites have a long history of coexistence with their hosts, but the equilibrium that existed between them was upset by the domestication of livestock, which occurred some $8,000-10,000$ years ago and by the subsequent intensification of herding practices (Sargison, 2012; Karlsson and Greeff, 2012).

Infections by GINs reduce the productivity and cause mortality of young animals, but the most significant losses are provoked by subclinical infections (Eysker and Ploeger, 2000). Environmental factors such as temperature and humidity affect the survival of the free-living forms of GINs in pastures, where around $95 \%$ of the population of these parasites is concentrated (Bowman, 2003), and where occurs egg laying, hatching and development of larvae, and ingestion by the host animals (Stromberg, 1997; O'Connor et al., 2006). Since the climate conditions that prevail in most of Brazil favor the development of GINs, the systematic use of anthelmintics has become a common practice in small ruminant herds, leading to the dissemination of resistance to the majority of chemical substances in use (Veríssimo et al., 2012; Cintra et al., 2016). Besides inefficacy, growing concern over the presence of drug residues in the environment and foods of animal origin has stimulated studies to find more innocuous anthelmintics, such as copper and plants extracts (Torres-Acosta and Hoste, 2008), as well as vaccines (Matos et al., 2017). Besides these, the use of diets with high protein levels, selective treatments, confinement in stables to reduce contact with infective parasite forms, and selection of more resistant sheep are among the control strategies used (Zvinorova et al., 2016). Genetic variation for resistance to GINs can be observed between and within breeds, allowing the identification of specific genes that contribute to this variation (Stear and Murray, 1994).

In small ruminant production systems, adaptation to environmental conditions, such as heat tolerance and the ability to survive numerous endemic disease challenges is considered a critical factor (Bishop, 2012). With increasing demand for sheep in Brazil's Southeast region,

\footnotetext{
* Corresponding author at: Embrapa Pecuária Sudeste, Rodovia Washington Luiz, Km 234, CP 339, 13560-970, São Carlos, SP, Brazil.

E-mail address: gigliotirodrigo@gmail.com (R. Giglioti).
} 
methods to control of GINs have been studied, and the use of more resistant breeds is considered a viable alternative (Mugambi et al., 1997; Rocha et al., 2005; Amarante et al., 2009; McManus et al., 2009; Ngere et al., 2017). Analysis of faecal egg counts (FEC) has been used in many experiments to characterize the resistance to GINs of small ruminants, finding heritability levels ranging from 0.01 to 0.65 (Zvinorova et al., 2016). The strategy of using cross-breeding to exploit the complementarity and heterosis between diverse sheep breeds can be an alternative to obtain more resistant animals. Therefore, this experiment was designed aiming to investigate the resistance to GINs of Santa Inês sheep, a breed considered to be highly resistant to these parasites (Amarante et al., 2004), in comparison with the Dorper, Ile de France and Texel breeds and crosses of these breeds with Santa Inês breed. The data obtained can support the identification of more resistant genetic groups to be selected in southeastern Brazil.

\section{Material and methods}

\subsection{Experimental area and animals}

The study was carried out on the experimental farm of the Embrapa Southeast Stock Breeding research unit (Embrapa Pecuária Sudeste), located in the municipality of São Carlos, São Paulo state (latitude $22^{\circ} 01^{\prime} \mathrm{S}$, longitude $47^{\circ} 53^{\prime} \mathrm{W}$ and $856 \mathrm{~m}$ above sea level). The climate in the region according to the Köppen scale is Cwa, characterized by relatively cool and dry winters and hot and rainy summers. The coolest period generally lasts from April to September. During 20 months (June 10, 2014 to January 11, 2016), 134 contemporaneous ewes of the genetic groups Santa Inês (OSI, $\mathrm{n}=16$ ), Dorper (ODO, $\mathrm{n}=12$ ), Texel (OTX, $n=13$ ) and Ile de France (OIF, $n=8$ ), along with crosses of $1 / 2$ OSI $+1 / 2$ ODO (ODS, $n=27$ ), $1 / 2$ OTX $+1 / 2$ OSI (OTS, $n=29$ ) and $1 / 2$ OIF $+1 / 2$ OSI (OIS, $n=29$ ) were monitored monthly. The female sheep were separated from their mothers at weaning at three months of age, and were reared together in a pasture area covering 6.0 ha planted with Tanzania grass, divided into two modules of 3 ha each and subdivided into four paddocks with 0.75 ha each, with grazing for 10 days followed by rest for 30 days, at a stocking rate of 22 animals per hectare. In the summer, the pastures received nitrogen fertilization $(150 \mathrm{~kg}$ of $\mathrm{N} / \mathrm{ha})$ and in the dry season the sheep were supplemented with corn silage. Water and mineral mixture were provided ad libitum. Monthy samples of feces were obtained to FEC and coprocultures and blood samples were used to measure the packed cell volume (PCV). To prevent mortality, the animals with FEC greater than or equal to 4000 and PCV lower than or equal to $21 \%$ were treated with a commercial anthelmintic - oral administration of a preparation based on levamisole chlorohydrate (Ripercol L, Fort Dodge) at a dose of $5 \mathrm{mg} \mathrm{p} / \mathrm{kg}$ of body weight. All the experimental protocols were approved by the committee on the ethical use of animals for experimentation of Embrapa Pecuária Sudeste (PRT no. 03/2013).

\subsection{Meteorological data}

The data on average monthly temperature $\left({ }^{\circ} \mathrm{C}\right)$ and total rainfall $(\mathrm{mm})$ were obtained from the climatology station of Embrapa Southeast Stock Breeding research unit, for the purpose of characterizing the climate variations during the experimental period.

\subsection{Collection and processing of the samples}

The fecal samples were collected directly from the rectal ampulla of each animal in labeled plastic bags. The samples were used to determine the FEC according to the modified technique of McMaster (Ueno and Gonçalves, 1998) with sensitivity of $50 \mathrm{eggs} / \mathrm{g}^{-1}$.

The eggs were counted under an optical microscope with $10 \mathrm{X}$ magnification.

To determine the nematode genera, coprocultures were prepared using $30 \mathrm{~g}$ of a pool of fecal samples collected from all animals of each genetic group, according to Roberts and O'Sullivan (1950). The infective larvae were identified according to Keith (1953), based on observation of 100 larvae, and the results were expressed as percentage of each genus found.

Simultaneously with the fecal samples, blood samples were obtained by puncture of the jugular vein and collection in tubes containing the anticoagulant EDTA. These samples were used to determine the packed cell volume (PCV) by the microhematocrit method. The values were expressed as percentage of red blood cells in the samples.

\subsection{Statistical analysis}

The FEC data were transformed into $\log _{10}(\mathrm{FEC}+1)$ to approximate the normal distribution. The FEC and PCV data were analyzed by mixed models that included repeated measures of the same animal. The fixed effects included in the model were genetic group and month by year of collection and their interactions, while the random effect was the animal within the genetic group. A variance and covariance matrix model with compound symmetry (CS) was used. This covariance structure was selected because it presented lower values in the Akaike's Information Criterion (AIC) and Bayesian Information Criterion (BIC) tests when compared to other structures such as the first order autoregressive or the unstructured covariance models. The repeatability was estimated as well as the residual correlations between FEC and PCV for each genetic group, using the same model, without month by year effect. The residuals were obtained by using the PROC MIXED option, and the Pearson correlation coefficients were calculated by the PROC CORR routine, in both cases using the SAS ${ }^{\circledast}$. The Tukey test was used to compare the means of the genetic groups.

\section{Results}

\subsection{Meteorological data}

Fig. 1 shows the monthly variations of the total rainfall according to month and year of the experiment. The total rainfall levels varied from $0.6 \mathrm{~mm}$ in August 2014 to $520.6 \mathrm{~mm}$ in January 2016. The average monthly temperatures (data not shown in the graph) ranged from $17.4^{\circ} \mathrm{C}$ in July 2014 to $24.6^{\circ} \mathrm{C}$ in January 2015 .

\subsection{GIN infections}

The statistical analyses revealed a significant effect $(p<0.05)$ of genetic group, collection month and interaction with the genetic group on the FEC counts. The lowest FEC average was observed for the OTS group, which differed from the other genetic groups $(p<0.05)$. The ODO group had the highest average FEC, but this did not differ significantly from OIF group ( $p>0.05$ ), which in turn did not differ from the other groups (Table 1). During the entire experimental period, the animals in the ODO group had the highest egg output, although a sharp decrease was observed in September 2015. The OSI group presented a large decline in the average FEC values in October 2015. The peak infection levels varied according to the genetic group, but in general occurred in September 2014, January and May 2015 and January 2016, which were months with the highest precipitation (Fig. 1).

The FEC counts during the experiment varied from zero to 17,000 (numbers not log-transformed). During the 20 months, 134 anthelmintic treatments were administered, according to the criteria established for the limits of FEC and PCV, of them 50 treatments in the ODO group, 31 in the ODS, 19 in the OIS, 14 in the OTX, 9 in the OIF, 7 in the OTS and 4 in the OSI.The repeatability values estimated for the different genetic groups (Table 1) indicate that under the conditions of this study, except for the OIF, OSI and OIS groups, which presented low values, all the others had moderate values. These moderate repeatability values estimated for the majority of the genetic groups indicate 


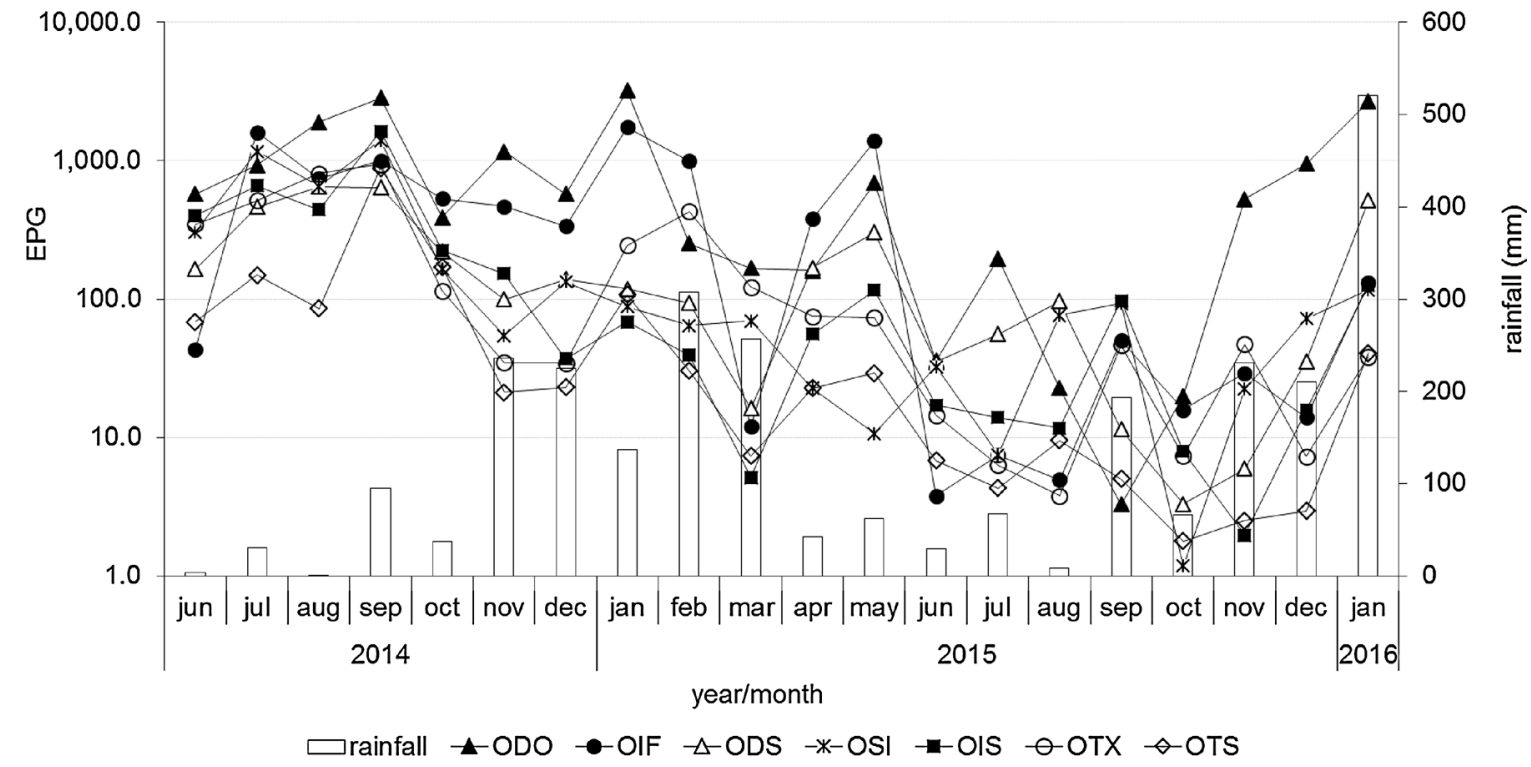

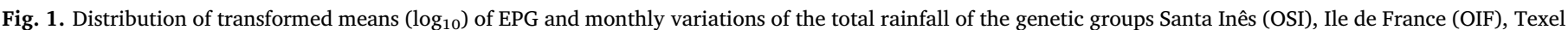

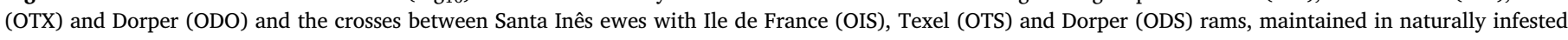
pastures from June 2014 to January 2016.

that under the conditions of this study, the average of each animal in a collection can be a good predictor of the measure for the same animal in the next collection (and vice versa).

The examination of the larvae recovered in the coprocultures showed mixed infections in the animals of all the genetic groups, with Haemonchus being the most prevalent genus along the experiment except in June/2014 and June/2015 (Fig. 2).

\subsection{PCV and correlations}

The mean PCV values differed significantly $(p<0.05)$ between the genetic groups studied (Table 1). The collection date and its interaction with genetic group also influenced the average PCV values ( $p<0.05$ ). The ODO genetic group presented the lowest PCV values, while the highest values were observed for the OIS animals, although this did not differ significantly from the means of the OSI and OTS groups.

The estimated correlation coefficients between FEC and PCV were negative and significant $(p<0.01)$ for the data observed $(-0.35)$ and also for the residuals of the statistical analyses $(-0.30)$. The correlations between FEC and PCV varied among the different genetic groups, with the highest correlations being observed in the ODO and ODS groups, while the lowest were found in the OIF and OTX (equal to zero) (Table 1). The correlations found for the majority of the groups revealed that an increase in the FEC number was accompanied by a reduction of the PCV values.

\section{Discussion}

This experiment was designed to investigate the resistance of sheep with different adaptive traits to GINs. The results of the FEC counts, coprocultures and PCV values were used to compare the OSI animals with those of the other genetic groups, not adapted, and their crosses, with all animals reared in the same pasture system.

The OTS animals presented the lowest average FEC values, even lower than found in the OSI genetic group. Our findings disagree with of other studies, which have found greater resistance of this Brazilian breed compared to crosses with sensitive breeds like Ile de France and Suffolk (Amarante et al., 2004) and Suffolk, Texel, Dorper and Ile de France (Amarante et al., 2009). Animals of the OSI breed are considered to be well adapted to Brazil's generally tropical conditions, and this was borne out in this study, since few animals of this breed had to be treated, mainly because their PCV levels remained above $20 \%$. On the other hand, our findings are in agreement with those of Rocha et al. (2005), which in an experiment also conducted in the state of São Paulo comparing the resistance to GINs in OSI and Ile de France lambs before weaning, found that both were susceptible to infections, and that the OSI animals had higher PCV levels, indicating greater capacity to withstand the adverse effects of parasitism. McManus et al. (2009), in an experiment conducted in the central region of Brazil, also observed that OSI animals were more susceptible to GINs than purebred Ile de France animals and crosses of OSI with Ile de France and Texel. In turn, Silva and Fonseca (2011) found that OSI animals had FEC levels that

Table 1

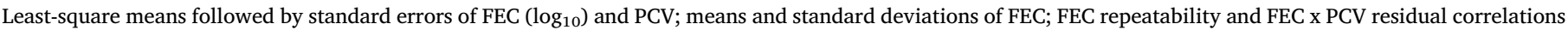
according to breed/cross.

\begin{tabular}{|c|c|c|c|c|c|}
\hline Genetic group & FEC $\left(\log _{10}\right)^{*}$ & untransformed FEC & $\mathrm{PCV}^{*}$ & FEC repeatability & Correlation FEC x PCV \\
\hline ODO $(n=10 / 166)$ & $2.51 \pm 0.17 c$ & $2356.1 \pm 3195.0$ & $27.00 \pm 0.63 c$ & 0.21 & -0.49 \\
\hline $\operatorname{OIF}(n=8 / 128)$ & $2.07 \pm 0.11 b c$ & $1095.1 \pm 2066.2$ & $29.78 \pm 0.75 b$ & 0.09 & -0.12 \\
\hline ODS $(n=27 / 469)$ & $1.94 \pm 0.11 b$ & $896.2 \pm 1691.2$ & $30.98 \pm 0.41 b$ & 0.33 & -0.42 \\
\hline OSI $(n=16 / 200)$ & $1.86 \pm 0.16 b$ & $657.3 \pm 935.1$ & $31.54 \pm 0.57 \mathrm{ab}$ & 0.15 & -0.23 \\
\hline OIS $(n=29 / 494)$ & $1.76 \pm 0.11 b$ & $648.6 \pm 1585.2$ & $32.34 \pm 0.39 a$ & 0.16 & -0.19 \\
\hline OTX $(n=10 / 162)$ & $1.82 \pm 0.17 \mathrm{~b}$ & $659.0 \pm 1320.3$ & $28.36 \pm 0.62 b c$ & 0.24 & -0.01 \\
\hline OTS $(n=25 / 476)$ & $1.35 \pm 0.11 \mathrm{a}$ & $371.3 \pm 911.2$ & $31.39 \pm 0.41 \mathrm{ab}$ & 0.38 & -0.36 \\
\hline
\end{tabular}

* Means followed by the same letters in the column do not differ from each other by Tukey test $(p>0.05)$. $\mathrm{n}=($ number of animals $/$ number of measures); ODO $=$ Dorper; OIF = Ile de France; OSI = Santa Inês; OTX = Texel; OIS = OSI x OIF; OTS = OSI x OTX; ODS = OSI x ODO. 


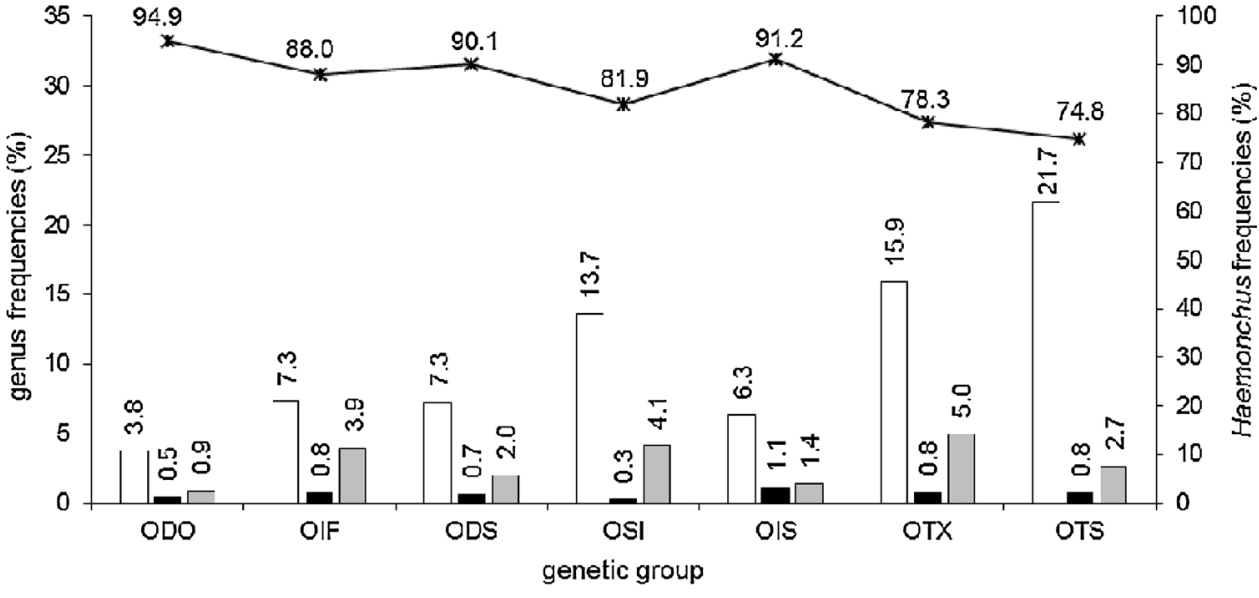

Fig. 2. Generic composition of infective nematode larvae identified in coprocultures of sheep of the breeds Santa Inês (OSI), Ile de France (OIF), Texel (OTX) and Dorper (ODO) and crosses between Santa Inês ewes and Ile de France (OIS), Texel (OTS) and Dorper (ODS) rams, kept in naturally infested pastures between June 2014 and January 2016. did not differ from those of Bergamácia animals, among a flock kept in pasture on a farm in the state of Rio de Janeiro, also in the Southeast region of Brazil. In the present study, was noted that the purebred animals of the non-adapted breeds presented two phenotypes: low resistance (ODO and OIF) and intermediate resistance (OTX). The OSI sheep showed resistance comparable to that of the OTX and ODS $\mathrm{x}$ OIS crosses. The OTS animals had a different pattern of infection than their parent OSI and OTX breeds. It is known that many factors can influence the susceptibility of sheep to GINs, such as age, immunological and nutritional state, and number of infective larvae in pastures (Stear et al., 2003; Roeber et al., 2013). In the present study, the animals were placed in paddocks just after weaning, and due to the stress caused by separation from the mothers and the greater susceptibility to GINs of this age (Amarante et al., 2004), they suffered from considerable infection levels.

Haemonchus and Trichostrongylus were the main parasite genera found in the coprocultures of all the genetic groups studied, with predominance of the former. Combined infection of parasites of these two genera has been described in various studies conducted with sheep in the same region as our experiment (Chagas et al., 2008), as well as in other regions of the state of São Paulo (Rocha et al., 2005; Louvandini et al., 2006; Amarante et al., 2009). We found that Haemonchus was predominant in the coprocultures of all the genetic groups, but the OTS group presented slightly less severe infection by parasites of this genus. Conversely, the OTS had the highest percentage of Trichostrongylus. As the former genus is a more spoliative parasite, this might have contributed to its good performance regarding PCV value, which did not differ from for the OSI group. It has previously been reported that Haemonchus females produce large quantities of eggs, increasing the FEC, while since they are hematophagous they reduce the PCV of the hosts (Eysker and Ploeger, 2000; Karlsson and Greeff, 2012). Nevertheless, sheep can survive with PCV levels as low as 20\% (Jain, 1993), especially when they are well nourished (Coop and Kyriazakis, 2001). This can explain the lack of mortality caused by GIN infections in this experiment. The ODS group stood out for maintaining the highest PCV levels under the same pasture infestation conditions, which can indicate strong resilience of these animals (Mugambi et al., 2005).

The estimated repeatability levels were moderate for the majority of the genetic groups. The estimated repeatability indicate that, except for the OTS and ODS group, the measure of each animal in a collection may not be a good predictor of the same animal's measure in subsequent collection, and so, to identify animals with stronger resistance to parasites within each genetic group, we must use the mean of several measures. The values we estimate were below those of Doligalska et al. (1997), who when evaluating the repeatability of nematode egg counts in the spring and autumn, found values of 0.52 and 0.41 , respectively.
They are also below those reported by Bouix et al. (1998), who found repeatability values in periods of the same year for ewes and lambs of 0.47 and 0.42 , respectively, while the repeatability value along the three years of the experiment was 0.25 . According to the authors, a possibility exists of genetic selection of sheep for resistance to nematodes where $H$. contortus is the dominant species. Our findings only partially support this conclusion.

The correlation coefficient between the FEC counts and PCV was negative, indicating that the reduction of the globular volume in the animals occurred at the same time as increases in the FEC. This was expected, since Haemonchus was the predominant genus in the coprocultures. Our findings corroborate those of Quirino et al., (2011) and Oliveira et al. (2008): both research teams found negative correlations between FEC and PCV, of -0.42 and -0.46 , respectively, in purebred OSI animals.

The results of this study showed that even with high FEC levels, the different genetic groups studied presented PCV values within the range considered normal; the selective anthelmintic treatments were able to prevent mortality in the flock and the OTS animals displaying significantly lower FEC during the experiment.

\section{Conflict of interest}

We declare that there is no conflict of interest in the present study.

\section{Acknowledgements}

This research project was supported by the São Paulo State Research Support Foundation (FAPESP) (Grant \#2011/51564-6) and the Brazilian Agricultural Research Corporation (Embrapa SEG 02.13.00.014.00.00).

\section{References}

Amarante, A.F.T., Bricarello, P.A., Rocha, R.A., Gennari, S.M., 2004. Resistance of Santa Inês, Suffolk and Ile de France lambs to naturally acquired gastrointestinal nematode infections. Vet. Parasitol. 120, 91-106.

Amarante, A.F.T., Susin, I., Rocha, R.A., Silva, M.B., Mendes, C.Q., Pires, A.V., 2009. Resistance of Santa Inês and crossbredewes to naturally acquired gastrointestinal nematode infections. Vet. Parasitol. 165, 273-280.

Bishop, S.C., 2012. A consideration of resistance and tolerance for ruminant nematode infections. Front. Genet. 3, 168.

Bouix, J., Krupinski, J., Rzepecki, R., Nowosad, B., Skrzyzala, I., Roborzynski, M., Fudalewicz-Niemczyk, W., Skalska, M., Malczewski, A., Gruner, L., 1998. Genetic resistance to gastrointestinal nematode parasites in Polish long-wool sheep. International J. for Parasitol. 28, 1797-1804.

Bowman, D., 2003. Georgi's Parasitology for Veterinarians, 8 ed. Saunders Publishing Company Missouri, St. Louis 422 pp.

Chagas, A.C.S., Vieira, L.S., Freitas, A.R., Araújo, M.R.A., Araújo-Filho, J.A., Araguão, 
W.R., Navarro, A.M.C., 2008. Anthelmintic efficacy of neem (Azadirachta indica a. juss) and the homeopathic product Fator Vermes in Morada Nova sheep. Vet. Parasitol. 151 (1), 68-73.

Cintra, M.C.R., Teixeira, V.N., Nascimento, L.V., Sotomaior, C.S., 2016. Lack of efficacy of monepantel against Trichostrongylus colubriformis in sheep in Brazil. Vet. Parasitol. 216, 4-6.

Coop, R.L., Kyriazakis, I., 2001. Influence of host nutrition on the development and consequences of nematode parasitism in ruminants. Trends Parasitol. 17, 325-330.

Doligalska, M., Moskwa, B., Niznikowski, R., 1997. The repeatability of faecal egg counts in Polish Wrzosówka sheep. Vet. Parasitol. 70, 241-246.

Emery, D.L., Hunt, P.W., Le Jambre, L.F., 2016. Haemonchus contortus: the then and now, and where to from here? Int. J. Parasitol. 46 (12), 755-769.

Eysker, M., Ploeger, H.W., 2000. Value of present diagnostic methods for gastrointestinal nematode infections in ruminants. Parasitology 120, 109-119.

JAIN, N.C., 1993. Essentials of Veterinary Hematology. Lea \& Febiger, Philadelphia 417pp.

Karlsson, L.J.E., Greeff, J.C., 2012. Genetic aspects of sheep parasitic diseases. Vet. Parasites 189, 104-112.

Keith, R.K., 1953. The differentiation of the infective larvae of some common nematode parasites of cattle. Aus. J. Zool. 1, 223-225.

Louvandini, H., Veloso, C.F.M., Paludo, G.R., Dell'porto, A., Gennari, S.M., Mcmanaus, C.M., 2006. Influence of protein supplementation on the resistance and resilience of Young hair sheep naturally infected with gastrointestinal nematodes during rainy seasons. Vet. Parasitol. 137 (1), 103-111.

Matos, A.F.I.M., Nobre, C.O.R., Monteiro, J.P., Bevilaqua, C.M.L., Smith, D.W., Teixeira, M., 2017. Attempt to control Haemonchus contortus in dairy goats with Barbervax ${ }^{\circledR}$, a vaccine derived from the nematode gut membrane glycoproteins. Small Rumin. Res. $151,1-4$.

McManus, C., Louvandini, H., Paiva, S.R., Oliveira, A.A., Azevedo, H.C., Melo, C.B., 2009. Genetic factors of sheep affecting gastrointestinal parasite infections in the Distrito Federal. Braz. Vet. Parasitol. 166, 308-313.

Mugambi, J.M., Bain, R.K., Wanyangu, S.W., et al., 1997. Resistance of four sheep breeds to natural and subsequent artificial Haemonchus contortus infection. Vet. Parasitol. 69 (2), 265-273.

Mugambi, J.M., Audho, J.O., Njomo, S., Baker, R.L., 2005. Evaluation of the phenotypic performance of a Red Maasai and Dorper double backcross resource population: indoor trickle challenge with Haemonchus contortus. Vet. Parasitol. 127 (3-4), 263-275.

Ngere, L., Burke, J.M., Notter, D.R., Morgan, J.L.M., 2017. Variance components for direct and maternal effects on body weights of Katahdin lambs. J. Anim. Sci. 95 (8), 3396-3405.

O'connor, L., Kahn, L.P., Walkden-Brown, S.W., Kahn, L.P., 2006. Ecology of the freeliving stages of major trichostrongylid parasites of sheep. Vet. Parasitol. 142, 1-15.
Oliveira, M.C.S., Chagas, A.C.S., Esteves, S.N., Giglioti, C., Giglioti, R., Ferrezini, J., Carvalho, C.O., Schiavone, D., 2008. Uso de tratamento seletivo contra gastrointestinal nematodes em ovelhas criadas em São Carlos, SP. Boletim de Pesquisa Desenvolvimento. Empresa Brasileira de Pesquisa Agropecuária (Embrapa) ISSN 1981-2078. 23p.

Perry, B.D., Randolph, T.F., McDermott, J.J., Sones, K.R., Thornton, P.K., 2002. Investing in Animal Health Research to Alleviate Poverty. ILRI (International Livestock Research Institute), Nairobi, Kenya 148pp.

Quirino, C.R., Carneiro-Silva, R.M., Costa, R.L.D., Madella-Oliveira, A.F., 2011. Correlations between weight, body condition score, Famacha, and eggs fecal counting in Santa Inês ewes. Actas Iberoamericanas de Conservación Anim. AICA 1, 319-322.

Roberts, F.H.S., O'Sullivan, J.P., 1950. Methods for egg counts and larval cultures for strongyles infesting the gastrointestinal tract of cattle. Aust. J. Agric. Res. 1, 99-102.

Rocha, R.A., Amarante, A.F., Bricarello, P.A., 2005. Resistance of Santa Inês and Ile de France suckling lambs to gastrointestinal nematode infections. Ver. Bras. de Parasitol. Vet. 4, 17-20.

Roeber, F., Jex, A.R., Gasser, R.B., 2013. Impact of gastrointestinal parasitic nematodes of sheep, and the role of advanced molecular tools for exploring epidemiology and drug resistance - an Australian perspective Florian. Parasites \& Vectors 6, 153.

Sargison, N.D., 2012. Pharmaceutical treatments of gastrointestinal nematode infections of sheep future of anthelmintic drugs. Vet. Parasitol. 189 (1), 79-84.

Silva, J.B., Fonseca, A.H., 2011. Susceptibility racial de ovinos a helmintos gastrintestinais. Semina: Ciências Agrárias, Londrina 32 (suplemento 1), 1935-1942.

Stear, M.J., Murray, M., 1994. Genetic resistance to parasitic disease: particularly of resistance in ruminants to gastrointestinal nematodes. Vet. Parasitol. 54, 161-176.

Stear, M.J., Bishop, S.C., Henderson, N.G., Scott, I., 2003. A key mechanism of pathogenesis in sheep infected with the nematode teladorsagia circumcincta. Anim. Health. Res. Rev. 4 (1), 45-52.

Stromberg, B.E., 1997. Environmental factors influencing transmission. Vet. Parasitol. 72 247-264.

Torres-Acosta, J.F.L., Hoste, H., 2008. Alternative or improved methods to limit gastrointestinal parastism in grazing sheep and goats. Small Rumin. Res. 77, 159-173.

Ueno, H., Gonçalves, P.C., 1998. Manual para o Diagnóstico de Helmintoses de ruminantes, 4th ed. Japan International Cooperation Agency, Tóquio 143pp.

Veríssimo, C.J., Niciura, S.C.M., Alberti, A.L.L., Rodrigues, C.F.C., Barbosa, C.M.P., Chiebao, D.P., Cardoso, D., Silva, G.S., Pereira, J.R., Margatho, L.F.F., Costa, L.R.D., Nardon, R.F., Ueno, T.E.H., Curci, V.C.L.M., Molento, M.B., 2012. Multidrug and multispecies resistance in sheep flocks from Sao Paulo state. Braz. Vet. Parasitol. $187,1-2$.

Zvinorova, P.I., Halimani, T.E., Muchadeyi, F.C., Matika, O., V, Riggio, Dzama, K., 2016. Breeding for resistance to gastrointestinal nematodes - the potential in low-input/ output small ruminant production systems. Vet. Parasitol. 225, 19-28. 